\title{
HERMANN VON HELMHOLTZ, EWALD HERING AND COLOR VISION: A CONTROVERSY OVER STYLES OF REASONING?
}

\author{
JULIANA GUTIÉRREZ ${ }^{1,2}$ \\ https:/ / orcid.org/0000-0002-5433-9080 \\ ${ }^{1}$ Universidad del Rosario - Escuela de Ciencias Humanas \\ Bogotá, D.C. \\ Colombia \\ ${ }^{2}$ Universidad de los Andes - Facultad de Ciencias Sociales \\ Department of Philosophy \\ Bogotá, D.C. \\ Colombia \\ j.gutierrezv@uniandes.edu.co
}

\begin{abstract}
Article info
CDD: 501

\section{Keywords \\ Scientific Controversy \\ Color Vision \\ Physiological Optics \\ Styles of Reasoning}

Received: 11.05.2020; Revised: 20.08.2020; Accepted: 07.10.2020

https://doi.org/10.1590/0100-6045.2021.V44N1.JG

Abstract: During the second half of the 19th century, in the field of physiological optics, there was a strong controversy between Hermann von Helmholtz and Ewald Hering. This controversy has been usually characterized as "empiricism" vs. "nativism". In the field of physiology of visual perception, several subjects demanded attention, among them, color vision. Helmholtz and Hering suggested different theories for the physiological correlate of color sensation and different color spaces to give an account of the relationships between colors. In this article, I will argue that the controversy between the two authors could be understood as differences between styles of reasoning, and these different styles 
express different presuppositions. More specifically, I want to suggest that the disagreements could be linked to the discussions on how vital phenomena should be studied.

\section{Introduction}

During the last decades of the $19^{\text {th }}$ century there was a significant controversy in the field of physiological optics. This controversy has usually been characterized as a disagreement between two parties, each with different theoretical focuses: nativism and empiricism. Each party had an important protagonist on its side: Hermann von Helmholtz (1821-1894) as an empiricist and Ewald Hering (1834-1918) as a nativist. On the one hand, nativism intended to explain most part of the phenomena of visual perception with innate physiological features of our sense organs. Empiricism, on the on the other hand (even though it also acknowledged that some phenomena of our visual perception were due to physiological features), gave more weight to the experiential history of the individual as fundamental in many aspects of our vision. Hering and Helmholtz's polemics cuts through the main subjects of the field. In the words of R. Steven Turner,

Helmholtz, Hering, and their schools disagreed on many issues, chief among them being the proper sense in which the eye may be said to possess and to require a mind with which to see. On this issue they disputed the basis of the human capacity to visually perceive space and to localize objects in that visual space. Is this capacity innate and present at birth (the nativist position), or is it gradually acquired through learning and individual experience and 
mediated by inferential processes (the empiricist position)? The question of the eye's mind impinged upon the two schools' disagreement about the probable receptor mechanisms that underlie color vision. Do these consist of three mechanisms producing respectively the sensations of three fundamental colors, which are then psychologically mixed to produce the full range of color experience? Or do they consist of three sets of antagonistic receptors, producing respectively the sensations black-white, redgreen, and yellow-blue? Can the eye's mind, in choosing among these alternatives, veridically assess the primitive or compound nature of its sensations? Do experience and inferential processes underlie the phenomena of contrast and adaptation, or are these produced by direct physiological mechanisms in the retina? [...] The schools' antagonistic interpretations of all of these phenomena grew out of deep and divergent methodological commitments and ultimately out of disparate conceptions of the nature of life and of organic function. (Turner, 1994, 3-4)

I agree with Turner's claim that the tensions between the two authors arise from methodological differences and diverse conceptions of the nature of their object of study. Which were these methodological differences? And furthermore, which were the conceptions that each of them had of the nature of life and the phenomenon that they wanted to unravel? If we explore a particular case of the controversy, maybe we will be able to shed a light on these deep tensions Turner mentions. I would like to focus on the 
controversy over color vision. Both Helmholtz and Hering offered different theories on the physiological correlates of color vision. Whilst the first offered a three-receptor theory of color vision (or the now known as "Young-Helmholtz theory"), the second offered an opponent-process theory -I will present the details more ahead-. The paths by which they arrived at their theories seem to follow a very different method. As we inquire into the ways in which they formulated their questions and approached their object of study, I argue that their differences were not only on a theoretical level (i.e. nativism and empiricism) but also on a stylistic level (referring to the category of "style of reasoning" from Ian Hacking).

The article will be structured in the following way. In the first two sections, I will briefly describe the terms in which the controversy has been presented (empiricism vs. nativism), the limits of this classical characterization for the case of color vision, and the categories that I will use to understand the tensions that divided the two authors, that is, styles of reasoning. In the third section, I will explain Hering and Helmholtz's theories, their arguments and the stylistic differences that one can identify between them. I claim that Helmholtz and Hering disagreed on the styles used to approach their object of study: both of them followed an experimental style, but, whilst Helmholtz adopted an analogical style, Hering refused to do so. Finally, I will argue that the differences between styles of reasoning between Helmholtz and Hering were due to deep presuppositions about the phenomenon of life and the way it should be studied. 


\section{The controversy as "Empiricism vs. nativism"}

The breakpoint in the controversy between empiricism and nativism was thought to turn on how much the eye needs or depends on a mind, or consciousness, to see. This characterization of the controversy was due, mainly, to Helmholtz himself (Turner, 1994, 80). Helmholtz, in the third volume of his Treatise on Physiological Optics (1866/1962), and in some other lectures, describes the heart of the controversy as a tension between these two poles. In the first chapter "Concerning perception in general" of the third volume of his treatise, Helmholtz presents the discussion in these words:

It may often be rather hard to say how much of our apperceptions as derived by the sense of sight is due directly to sensation, and how much of them, on the other hand, is due to experience and training. The main point of the controversy between various investigators in this territory is connected also with this difficulty. Some are disposed to concede to the influence of experience as much scope as possible, and to derive from it especially all notion of space. This view may be called the empirical theory (empiristische Theorie). Others, of course, are obliged to admit the influence of experience in the case of certain classes of perceptions; still, with respect to certain elementary apperceptions that occur uniformly in the case of all observers, they believe it is necessary to assume a system of innate apperceptions that are not based on experience [...]. In contradistinction to the former view, this may perhaps be called the intuition theory 
(nativistische Theorie) of the sense-perceptions. (Helmholtz, 1866, v. 3, 10)

Thus, the empirical view adopts the following methodological corollary: "Whatever, therefore, can be overcome by factors of experience, we must consider as being itself the product of experience and training. By observing this rule, we shall find that it is merely the qualities of the sensation that are to be considered as real, pure sensation." (Helmholtz, 1866/1962, v. 3, 13. Emphasis of my own). This position conceives sensations as signs of the external world that we then interpret and organize thanks to experience and memory (Helmholtz, $1868 / 1995,177)$. In that sense, an observer has to make unconscious inferences [unbewusster Schlïsse], as Helmholtz has called them, in order to organize his visual perception. These inferences are unconscious processes of association (or induction) using past sensations. (Helmholtz, 1866/1962 v. 3, 26-27). Accordingly, Helmholtz makes a fine distinction between sensation and perception. Sensation occurs when external agents [stimuli] act on the sensory nerves, provided the nerves are alive and connected to the brain, which is the organ of consciousness. (Helmholtz, 1866/1962, v. 2, 1). Perception is the meaning attributed to sensations -a meaning which is inferred unconsciously from experience-. "The sensations aroused by light in the nervous mechanism of vision enable us to form conceptions as to the existence, form and position of external objects. These ideas are called visual perceptions." (Helmholtz, 1866/1962, v. 3, 1. Emphasis of my own). For Helmholtz, "[t]he fundamental thesis of the empirical theory is: The sensations of the senses are tokens for our consciousness, it being left to our intelligence to learn how to comprehend their meaning." (Helmholtz, 1866/1962, v. 3, 533).

On the other hand, following Helmholtz's description, the nativist view aims to minimize (as much as possible) the 
role of experience, postulating innate physiological mechanisms to explain phenomena that could be explained in terms of psychological laws, even though this latter strategy is, according to the author, less "audacious and dubious". (Helmholtz, 1878/1995, 357). Nativism, then, believes that the scope of what Helmholtz calls "perception" is not as wide as the empiricists defend: there is a lot of our visual experience that is directly given through sensation thanks to the physiological features of our sensory-nervesand not learned. However, for the author, nativism has to assume a preestablished harmony between the laws of the mental and the laws of the physical world, while for empiricism, the correspondence between the mental and the external world is acquired by experience and learning (Helmholtz, 1868/1995, 177). According to Helmholtz, nativism does not explain our visual perception; what it simply does is to posit unnecessary innate physiological processes that go against what the laws of physics have established:

The empirical theory attempts to prove that at least no other forces are necessary for their origin [the origin of sense-perceptions] beyond the known faculties of the mind, although these forces themselves may remain entirely unexplained. Now, generally it is a useful rule in scientific investigation not to make any new bypothesis so long as known facts seem adequate for the explanation, and the necessity of new assumptions has not been demonstrated. That is why I have thought it incumbent to prefer the empirical view essentially. Still less does the intuition theory attempt to give any explanation of the origin of our perceptual images; for it simply plunges right into de midst of the matter by assuming 
that certain perceptual images of space would be produced directly by an innate mechanism, provided certain nerve fibers were stimulated. (Helmholtz, 1866/1962, v. 3, 17. Emphasis of my own).

And just a few lines ahead, the scientist links Hering to this rival view: "In its more recent development [of the nativist view], especially as formulated by E. Hering, there is a hypothetical subjective visual space, wherein the sensations of the separate nerve fibers are supposed to be registered according to certain intuitive laws." (Helmholtz, 1866/1962, v. 3,17$)$.

Hering never agreed with this characterization. For him, Helmholtz's tension between empiricism and nativism was not a real opposition; both "empiricists" and "nativists" conceded a role to innate physiological mechanisms and to experience. "Helmholtz has called my view "nativist" in contraposition to the one he defends, which he calls "empiricist". These designations are not at all adequate, for they turn a minor point into the main matter. Between "nativism" and "empiricism" there is not a fundamental difference, only a difference of degree." (Hering, 1878, 3). According to Hering, the heart of the dispute was the conflict between what he identified as a spiritualist tendency [spiritualistischen Richtung] and a physiological tendency. The former attempted to restrict the realm of the innate to provide a greater place for the human spirit. For Hering, those who sided with this view, when faced with trouble explaining certain phenomena, appealed to "the soul", or "judgement", or "consciousness" as a deus ex machina in order to eliminate the difficulties. Hence, given that many sensory phenomena were elusive to the explanations offered by physics and chemistry, there were many who leaned towards a spiritualist tendency. The author believed that "empiricists", 
following Helmholtz's terms, had a preference for this spiritualist inclination (Hering, 1878, 2-3). The physiological tendency, on the contrary, viewed all phenomena of consciousness as determined by organic processes. Hence, all sensory facts must always count on some physiological correlate. ${ }^{1}$ This view expected to offer a physiology of consciousness or, better yet, a physiological psychology (Turner, 1994, 122-123). In Hering's words,

[t]hus considered, phenomena of consciousness appear to be functions of material changes of organized substance, and vice versa. [...] Aided by this hypothesis of a functional connection between spiritual and material facts, modern physiology is enabled to bring the phenomena of consciousness within the domain of its inquiry, without leaving the terra firma of scientific method. (Hering, 1897, $5) .^{2}$

${ }^{1}$ See Heidelberger (1993b) on Helmholtz's idealism. According to him, many of Helmholtz's contemporaries viewed his stance as an idealistic one: "It was for this reason why he so bristled when critics, like Ewald Hering, of his theory of sense perception charged him with being a spiritualist." (494).

${ }^{2}$ Hering's ideas were strongly linked to theories postulated by physiologists such as Gustav Fechner. Fechner himself acknowledged that his viewpoints were very close to the monistic ideas of Spinoza and Schelling. In other words, Fechner sustained something similar to a panpsychism: the whole world was animated or had mental features (Fechner, 1836/2005; Heidelberger, 1993a). In addition, Ernst Mach, who was a colleague of Hering at the University of Prague for 25 years, shared a lot of Hering's views regarding his investigations on sensations: "[f]or all psychically observable details of $B$ [sensation] we have to seek the corresponding physical details of $N$ [nerve-process]. We may thus 
Now, for the particular case of color vision, can the disagreements between Helmholtz and Hering be understood in terms of nativism vs empiricism? Color belongs mainly, following Helmholtz's categories, to the realm of sensation. Accordingly, the second volume of his Treatise where he develops his theory of color vision is titled "The Theory of the Sensations of Vision". ${ }^{3}$ And in order to understand the qualities of the sensations of light (color and luminosity), one must do, above all, physiology. Helmholtz adopts Johannes Müller's law of specific nerve energies (Müller, 1843, 707-709; De Kock, 2014): "the nature of a sensation depends primarily on the peculiar characteristics of the (receptor) nervous mechanism." (Helmholtz, 1866/1962, v. 2, 4). Hering also follows Müller on this point (Hering, 1897; 1900). Therefore, one must study the features of nervous mechanisms if one wants to explain the qualities of light sensation. The qualities of our sensations of light are,

establish a guiding principal for our investigations, which may be termed the principle of the complete parallelism of the psychical and physical." (Mach, 1897, 30).

3 According to Helmholtz's view, there are phenomena of color vision that are not precisely "sensations". However, this part of Helmholtz's treatise seems to go in a very different direction in comparison to the rest of the second volume in which he tries to give a strictly physiological account. In that aspect, I agree with Kremer (1993): "Only when considering subjective colors did Helmholtz encounter limits for Young's hypothesis [physiological hypothesis]. To explain such colors Helmholtz was forced to supplement [his] mechanisms with hypotheses about mental processes of "judgments" [...]. By attributing some subjective phenomena to strictly physiological mechanisms and others to combined physiological and psychological processes, however, Helmholtz clouded the methodological clarity and simplicity that he had achieved [...] in other areas of color vision." (251). 
following this physiological stance, a mere form of intuition ${ }^{4}$ (Helmholtz, 1868/1995, p. 348), for they are determined and given by physiological innate characteristics which are prior to all experience:

the investigations in sensory physiology -that (above all) Johannes Müller completed, critically envisioned, and then summarized in the law of specific energies of sensory nerveshave now brought the fullest confirmation [...] and thereby at once presented and made evident the nature and meaning of one such $a$ priori, subjective form of sensation in a very decisive and tangible way. (Helmholtz, 1868/1995, p. 345)

Thus, as intuition, color sensation -to some extent- is "simply given" by the nature of our sensory-nerves and "comes about without reflection and seeking" (Helmholtz, $1878 / 1995,352)$. It seems, then, that in this aspect both Helmholtz and Hering agreed: there are certain physiological mechanisms that explain the qualities of our light sensations. There were, certainly, some phenomena of color which generated controversy over whether they were learned or determined by innate features (phenomena of contrast, color constancy and the use of color in space perception). However, Hering and Helmholtz not only differed on that level; they disagreed on precisely the innate physiological

\footnotetext{
${ }^{4}$ According to De Kock (2014), "Helmholtz was one of the first to give Müller's Law its Kantian interpretation, and is therefore credited by some as one of the earliest figures of so-called physiological neo-Kantianism, i.e., the early neo-Kantian movement $[\ldots]$ that developed from the physiological interpretation to Kant's a priori." (718).
} 
mechanisms that explain color sensations. Therefore, in my opinion, while this description of the controversy can be illuminating when it comes to visual perception, it is inadequate to understand the dispute over the different theories regarding physiological mechanisms underlying color sensation. The reason why the authors preferred some mechanisms over others cannot be clarified by understanding the whole debate as it has been traditionally portrayed. I believe that the differences between the two could be traced back to stylistic matters. ${ }^{5}$

Each author offered a theory for color vision and, particularly, color sensation; and their investigations were developed very differently. On the one hand, Helmholtz adopted the mathematical model postulated by Isaac Newton (1717/1977), the color circle, and added the mathematical sophistications made by Hermann Günther Grassmann to the model (1854) and the empirical information gathered by James C. Maxwell (1855) (Turner, 1996). After laying out a color chart with these elements, he went on to suggest the physiological correlates

\footnotetext{
${ }^{5}$ As I said, according to Helmholtz's view, there are phenomena of color vision that are not precisely "sensations". However, this part of Helmholtz's treatise seems to go in a very different direction in comparison to the rest of the second volume in which he tries to give a strictly physiological account. In that aspect, I agree with Kremer (1993): "Only when considering subjective colors did Helmholtz encounter limits for Young's hypothesis [physiological hypothesis]. To explain such colors Helmholtz was forced to supplement [his] mechanisms with hypotheses about mental processes of "judgments" [...]. By attributing some subjective phenomena to strictly physiological mechanisms and others to combined physiological and psychological processes, however, Helmholtz clouded the methodological clarity and simplicity that he had achieved [...] in other areas of color vision." (251).
} 
corresponding to the fundamental variables used to build the chart. Helmholtz embraced Thomas Young's hypothesis of the existence of three types of sensitive filaments, each corresponding to one of three primary colors (Young, 1802). Following this path, the author identified three primary colors or sensations, i.e., green, red and violet, from which we can obtain all the rest (Helmholtz, 1868/1995, 346); and, furthermore, he posited three physiological processes or fibers, each of them particularly sensible to green, red or violet light rays. ${ }^{6}$ This is now known as the three-component theory of color vision or the "Young-Helmholtz theory". On the other hand, Hering adopted a method that seemed to evoke a tradition settled by Goethe: he observed the phenomenon of color as color itself, and from this observation he dug out what he believed were the fundamental variables or laws underlying the phenomenon (the primordial phenomenon [Urphänomen] in the words of Goethe). In that order of ideas, his investigation began with a phenomenological analysis of color; that is, he first studied color as a visual quality (using Hering's own terms) to identify the minimum phenomenological variables with which we could give an account of all observable colors and then built a color space (or chart) (Hering, 1872/1964, 24-25). Then, he suggested a physiological correlate for each of these variables. By doing this, Hering established four primary chromatic colors organized as pairs of contraries red-green and yellow- blue, and two contrary primary achromatic colors, black-white. Hering's physiological hypothesis is that in our sense organs there are three processes that correspond to

${ }^{6}$ The order of this presentation is close to Helmholtz's own exposition of his theory in the second volume of the Treatise. See especially section $\$ 20$ of the Treatise.

Manuscrito - Rev. Int. Fil. Campinas, v. 44, n. 1, pp. 37-97, Jan.-Mar. 2021. 
each pair of opposites. ${ }^{7}$ This hypothesis is now known as the opponent-process theory of color vision. Thus, Hering and Helmholtz suggested rival physiological hypothesis for the account of color sensation. ${ }^{8}$

In my opinion, these disagreements are an expression of deep differences concerning the way life and phenomena of consciousness should be studied. These tensions were present not only in their discussions but also in all fields of physiology during the $19^{\text {th }}$ century in Germany, and I believe they determined different styles of scientific reasoning both in Hering and in Helmholtz's investigations. In Helmholtz's case, we find a reductionist stand that opposed any form of vitalism. His aim was to explain the vital and sensory phenomena as much as possible with the tools of physics and chemistry alone (Cranefield, 1957; Temkin, 1946). In his own words, "[p]hysiologists, then, must expect to meet with an unconditional conformity to law of the forces of nature in their inquiry respecting the vital processes; they will have to apply themselves to the investigation of the physical and the chemical processes going on within the organism." (Helmholtz, 1869/1995, 217). In Hering's case, we encounter a very skeptical stance respecting Helmholtz's reductionism 9 . He considered it inadequate to study life from our knowledge of lifeless phenomena:

\footnotetext{
7 The order of this presentation is also close to Hering's own presentation of his theory. See especially chapters II and IV of Hering (1872/1964).

8 Any insinuated theory had to explain, among other things, phenomena such as color blindness, after-images, color constancy and contrast too. The differences over last two can be understood, indeed, in terms of nativism vs empiricism.

${ }^{9}$ It is important to keep in mind that Helmholtz's reductionism is not a reductionism of mental phenomena to physical phenomena.
} 
Let us cease considering physiology merely as a sort of applied physics and chemistry and thus avoid arousing the justifiable opposition of those who believe it to be an idle task to seek an exhaustive explanation of the living from the dead. Life can be fully understood only from life, and a Physics and a Chemistry which have sprung solely from the domain of the inanimate nature, and which therefore apply solely to inanimate nature, are adequate only to the explanation of such things as are common to the living and the dead. (Hering, 1900, 169)

Taking all of this into account, I will argue that Hering and Helmholtz, regarding color sensation, followed different styles of reasoning which were, at the same time, a consequence of the presuppositions that each of them had of vital and mental phenomena and how they should be studied.

The mental realm, for the author, remained autonomous. His reductionism was concerning vital phenomena: form him, every vital process had to be explained in physical and chemical terms. According to Heidelberger (1993), for Helmholtz, organic and inorganic processes had to be reducible to physical forces; the mind did not have to be, and could not have been, reduced to mechanics. Thus, "Helmholtz's physiological reductionism strictly separated mind and its principles from the world of matter" (Heidelberger, 1993b, 493). 


\section{II. "Styles of reasoning" as a category to understand the controversy}

The category "style of reasoning" has a long history and different mother concepts. Ian Hacking acknowledges the influences of philosophers such as Ludwik Fleck (1979) and Alistair Crombie $(1994)^{10}$. Fleck used the idea "thought style" and "thought collective", and Crombie suggested the term "style of thinking". Both concepts are closely linked: in a certain way, they are talking about the limits of what can be thought or, better yet, affirmed; thus, a style of thought or of thinking makes possible certain propositions and establishes others as unthinkable. However, Fleck's category is more restrictive to a field of inquiry or discipline (Hacking, 1992a, 3); Crombie's and Hacking's categories are larger in scope. Styles, for both of them, transcend their disciplines, their places and moments of birth, and even the humans that first practiced it. "Every style comes into being by little microsocial interactions and negotiations. It is a contingent matter to be described by historians [...]. Yet each style has become independent of its own history. We can forget the history or enshrine it in myth.” (Hacking, 1992a, 10).

Nonetheless, Hacking decided to change "thinking" for "reasoning". While thinking has an echo of a psychological or private aspect, reasoning is something that is done both in public and in private; it is done by thinking, but also by talking, arguing and showing. (Hacking, 1992a, 3). Hacking's aim with styles of reasoning as a tool of analysis is not only to

${ }^{10}$ Crombie came up with the concept of "style of thinking" to make an emphasis on the methods and strategies followed by the European scientific tradition. His most famous work are the three volumes of the Styles of Scientific Thinking in the European Tradition (1994).

Manuscrito - Rev. Int. Fil. Campinas, v. 44, n. 1, pp. 37-97, Jan.-Mar. 2021. 
understand how scientists work or think. Science is a social and historical enterprise that relies on a whole apparatus of people, instruments, theories and practices that are supposed to assure some sort of objectivity. Hacking's fundamental question is how is objectivity possible. In other words, how is knowledge, and most of all, scientific knowledge, about the world possible.

My styles of reasoning, eminently public, are part of what we need to understand what we call objectivity. This is not because styles are objective (i.e. we have found the best impartial ways to get at the truth), but because they have settled what it is to be objective (truths of certain sorts are just what we obtain by conducting certain sorts of investigations, answering to certain standards). (Hacking, 1992a, 4)

Therefore, for Hacking, a style is what defines which propositions have sense within a scientific practice. In other words, a style delimits a horizon of possibilities, that is, it postulates the candidates for being true or false, and it also determines how we can decide on the truth or falsehood of those statements. Thus, styles are not just ways of justifying our claims, but they also regulate what can be subject for justification, confirmation or verification, what sort of objects can we talk about, how can we talk about those objects, and, additionally, what sort of claims can count as a reason or evidence in favor of the truth of a proposition. (Hacking, 1992a). ${ }^{11}$ In the context of scientific practice,

\footnotetext{
${ }^{11}$ For that reason, Hacking is not referring to logic: deduction and induction are ways of preserving truth; they are devices that work only when the statements taken as true are given. (Hacking, 1982, 58)
} 
"there are neither sentences that are candidates for truth, nor independently identified objects to be correct about, prior to the development of a style of reasoning." (Hacking, 1992a, 11). Nevertheless, the settlement of their truth or falsehood does not depend on the style. It is important to keep in mind that styles do not entail the truth value of the sentences they make possible; they only provide the conditions where truth can be objectively determined. Hence, truth is external to a style of reasoning. (Hacking 1992b, 135) ${ }^{12}$.

Hacking listed the following styles of reasoning (keeping in mind the ones that also had identified Crombie and added (vii) and (viii)) (Hacking, 1992a):

(i) Geometrical style (which consists on postulating axiomatic systems)

(ii) Experimental style (which consists on elaborating sophisticated experimental strategies in order to make controlled observations and measurements)

(iii) Analogical style (which consists on building abstract models of the phenomenon under study)

(iv) Taxonomical style (which consists on ordering a variety from comparison and taxonomy)

(v) Statistical style (which consists on studying regularities with the help of statistical calculus and probabilistic calculus)

${ }^{12}$ It is important to keep in mind that Hacking does not commit to one theory of truth. There are sentences, such as observation statements, whose truth can be assessed just by looking and to which a correspondence theory applies. (Hacking, 1992b, 133135). 
(vi) "Evolutive" style (which consists on making a historic derivation from genetic developments)

(vii) Laboratory style

(viii) Algorithmic style

These styles were all born within a particular time and scientific community. However, all of them became independent from their conditions of birth: they established what could be considered as scientific knowledge, and, moreover, they were successful at attaining this knowledge. "The style ends as an autonomous way of being objective about a wide class of facts, armed with its own authority, and available as a neutral tool for any project or ideology that seeks to deploy it. It provides new criteria of truth, new grounds of belief, new objects about which there can be knowledge.” (Hacking, 1992b, 133).

For Hacking, styles are not contradictory as conceptual schemes may be nor incommensurable as Kuhnian paradigms. Styles entail a set of possible assertions about the world, but they do not imply a set of assertions taken as being true. In that sense, a particular scientific community practicing a style does not necessarily denies what others, with a different scientific style, affirm. Furthermore, communities sharing a style could differ on the truth value of a proposition. Therefore, we can encounter situations where different styles coexist peacefully in the same discipline, or situations where the differences are so immense that some propositions entailed by one style could be nonsense in the other. However, this last scenario is not an example of incommensurability, for we can always understand: we can learn to reason as the other group of scientists does; we can study their practices and recognize what class of assertions are considered as possible knowledge, even without granting their status of "objective 
knowledge". (Hacking, 1982, 60). Now, if two contemporary parties belonging to the same field of inquiry disagree in style, what would be the features of this sort of quarrel? They would disagree precisely on what can be said (what is a scientific proposition and what is mere speculation), on what can count as evidence (if a proposition is well justified or not), on what sort of objects can be posited to offer explanations, and on what sort of entities we can talk about. In fewer words, they would disagree on what can be considered as scientific knowledge. This is the case of Helmholtz and Hering.

Helmholtz and Hering played an important role in the emergence of experimental physiology, and both tried to move away from the romantic tradition and from Schelling's Naturphilosophie that had strongly influenced physiology, medicine and the life sciences in general during the end of the $18^{\text {th }}$ century and the first half of the $19^{\text {th }}$ century. As a response to these romantic and philosophical movements in the scientific territory, the experimental physiology offered a different way to approach vital phenomena, and it began to develop in the middle of the $19^{\text {th }}$ century. But, as in every transition, many questions remained open. How should we conceive and make experiments? What variables do we need to control? What sort of phenomena are we trying to unravel? Hence, while establishing a new style within a particular science, many problems can emerge regarding how the community must continue with its activity. Hering and Helmholtz take separate paths at this crossroads. Hering demanded an investigation where it was the phenomenon itself the one that gave away the clues for the scientist to organize and structure it. Following this maxim, he insisted on the autonomous and special status of all vital processes: life can be fully understood only from life. Helmholtz, on the contrary, allowed the introduction of models conceived by 
mathematics and physics in order to organize and structure the phenomena under study. All of this with the hope of reaching a unity of science and finding a unique science to explain all possible phenomena in the realm of the animate and the inanimate. For this reason, Helmholtz used an experimental and an analogical style, whereas Hering adopted the experimental style and strongly opposed adopting the models of other sciences in the explanation of phenomena that, according to him, needed their own categories. As I will try to show, all of these tensions can be found in their studies on color vision and, especially, on color sensation. I think that if we understand the controversy in these terms, many aspects of the dispute can be elucidated.

What are the particular features of the experimental and the analogical styles? In the experimental style, (i) scientists produce situations where they can control (and even reduce) the complexity of the phenomena under study, (ii) these situations have to be able to be reproduced by other scientists, (iii) and there has to be competent and reliable witnesses. ${ }^{13}$ In the analogical style (i) scientists start with a model (that can be taken from other fields) that structures the phenomena under study, (ii) this model is the one that indicates which are the variables that must be taken into account, that defines what sort of questions can be asked, what sort of explanations can be offered and what type of descriptions can be made. My goal is to identify these features in Helmholtz's and Hering's investigations in order to understand and characterize their dispute.

\footnotetext{
${ }^{13}$ A shrewd historical study on the emergence of the experimental style can be found in Shapin and Schaffer's work, Leviathan and the Air-Pump (1985).
}

Manuscrito - Rev. Int. Fil. Campinas, v. 44, n. 1, pp. 37-97, Jan.-Mar. 2021. 


\section{Studies on color vision}

In the studies on color vision and, particularly, color sensation, three questions were fundamental. First, -keeping in mind that colors are not a property of the objects themselves but something that results from the way objects, and the light they reflect, affect our eyes and our perceptual system (in agreement with Müller's law) - what physiological and physical processes in our sense organs allow the sensation of color? Second, how is it possible to conceive all colors from a set of primary colors? And third, which are the relations of difference and similarity between the colors we see, and what are the criteria to define these relations? To answer the two latter questions, both of them, starting with a set of primary colors, conceived a color space or cartography in order to represent the way colors organize and relate to each other. To answer the first question, both suggested a physiological correlate to explain color vision taking into account the variables with which they built their cartography, and, additionally, the two scientists made experiments (or took empirical evidence gathered by others) to defend their hypothesis. Throughout this agenda, one can see the tensions that I want to bring to light. Next, I'll present each of their theories and their arguments.

\section{Hermann von Helmholtz}

Helmholtz begins his investigation adopting an undulatory theory of light: the colors we see when white light passes through a prism are produced by light rays of different wavelengths and different degrees of refrangibility affecting our eyes. (Helmholtz 1860/1962, v. 2, 61; Helmholtz, 1869/1995, 154). In Helmholtz's words, “In general, then, light, which consists of undulations of different wave- 
lengths, produces different impressions upon our eye, namely, those of different colors." (Helmholtz, 1968/1995, 154). Homogenous rays ${ }^{14}$ of different wavelength can be combined in order to produce the sensation of prismatic colors and other colors such as purple (which is not prismatic $)^{15}$. Additionally, Helmholtz takes Newton's mathematical instrument to represent all colors, their relations of neighborhood and the laws of color mixture; he also embraces Grassmann's (1854) modifications to Newton's model and uses the empirical evidence collected by Maxwell (1855).

Newton devised an instrument in order to organize all colors in a space delimited by a closed curve; for him, the curve was a circumference. The prismatic hues are represented on the circumference in the same order as they appear in the prismatic dispersion; red and violet are linked by the non-prismatic color purple, and white is located at the center (Figure 1). The circle represents all colors that go from white to the "purest" or most saturated colors (that is, the colors less contaminated by white) which are located on the circumference. According to Newton, all colors are in this

\footnotetext{
14 A homogeneous ray is a pure kind of light with a determined wavelength which is not combined with any other ray of the spectrum with different wavelength. (Helmholtz 1860/1962, v. 2, $62,77,120)$.

15 Hence, Helmholtz makes the distinction between compound colors and simple colors: for him, it is possible to have a pure orange when we isolate the rays that produce this impression and, additionally, we can have a compound orange by mixing rays of different wavelengths. An observer cannot tell the difference between a simple color and a compound color (Helmhotlz, 1962, v. 2, 120). This problem is generally known as the problem of metamers.
}

Manuscrito - Rev. Int. Fil. Campinas, v. 44, n. 1, pp. 37-97, Jan.-Mar. 2021. 
circle, and all of them are either produced by "pure" or homogeneous lights, or by combinations of them: "all the colors in the universe which are made by light, and depend not on the power of imagination, are either the colors of homogeneous lights, or compounded of these and that either accurately or very nearly, according to the rule of the foregoing problem [i.e. the color circle]." (1704, Book 1, part II, prop. VII, theor. V). Newton establishes seven simple colors by making an analogy between the series of colors and the music scale which has seven tones: red, orange, yellow, green, blue, indigo and violet. Each simple color on the circumference occupies a space proportional to the space they occupy in the prismatic dispersion, and in the middle of each arc, Newton places what he calls the "center of gravity" of the color. If we draw a straight line between two colors that we wish to combine, and we assign the weight or quantity that we want to add from each color, we can determine the "center of gravity" of the compound color. If we then draw a ray from the center of the circle passing through the center of gravity of the compound color until it cuts the circumference, the point where this ray cuts the circumference indicates the hue of the combination. The distance from the center of the circle to the center of gravity of the combination represents the degree of "intensity" or saturation of the color; the farther from the center of the circle, the more saturated (or purer) the color will be, and the closer to the center, the more pale or whitish it will be. Every hue from the prismatic dispersion can be obtained by mixing pairs of colors; it is not possible to obtain a new hue different from the ones placed in the circumference (besides purple) by mixing more than two simple colors. 


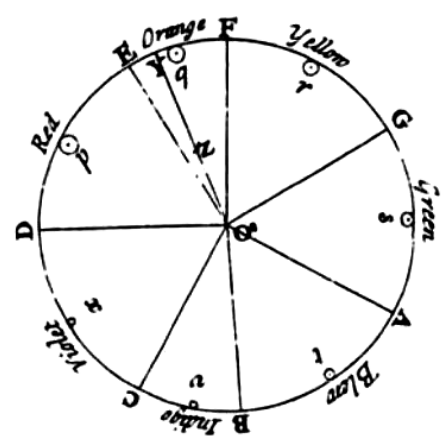

Figure 1. Newton's color circle ${ }^{16}$

Following Grassmann's work, Helmholtz proves that Newton's circle can be obtained by taking three variables that are present in any color sensation, that is, (i) saturation, (ii) bue and (iii) brightness or luminosity (Helmholtz, 1860/1962, v. 2, 132) ${ }^{17}$. Moreover, keeping in mind Maxwell's experiments (1855), Helmholtz argues that it is possible to build this same color space from three primary colors which can be randomly chosen with the condition that with the mixture of two, one cannot produce the third color (Helmholtz, 1869, 1962, v. 2, 134, 141). The spaces constructed from three primary colors or from the three variables mentioned are all equivalent to Newton's instrument and entail the method of centers of gravity. Therefore, the color chart can be made with at least three

${ }^{16}$ Newton, 1717/1977, 137.

${ }^{17}$ Grassmann showed that the method of centers of gravity is equivalent to the construction of a vectorial space of three dimensions. Thus, the color space can be obtained by laying out a system of coordiates of three dimensions or by picking three samples of color chosen as primary to obtain the rest.

Manuscrito - Rev. Int. Fil. Campinas, v. 44, n. 1, pp. 37-97, Jan.-Mar. 2021. 
variables. With all of these elements at hand, the author sets out to make a color chart.

He begins with a triangle. Each color designated as primary is located on a vertex of the triangle (Figure 2). Following the method of the centers of gravity, one must identify the place of every color that can be produced by mixing the three primary ones. Thus, all colors that come from the mixtures of the colors $A$ and $B$ are found in the line $A B$, all the ones that come from the mixtures of $B$ and $C$ are found in the line $B C$, and all the ones that come from the mixtures of $A C$ are found in the line $A C$. Most of the mixtures of $A, B$ and $C$ are located inside the triangle. However, some colors, as we will see more ahead, can be placed outside. These last colors are conceived from "negative weights" associated to the primary colors. In other words, I could combine - $\alpha$ times $A, \beta$ times $B$, and $\mu$ times $C$ to produce a compound color with $\phi$ times the color $M$, i.e., $-\alpha A+\beta B+\mu C=\phi M$. Now, how do we interpret these negative weights assigned to a primary color? If we take this equation, we could simply rewrite it in such a way that the negative coefficient associated to $A$ stays positive by putting it in the other side of the equation, that is, $\beta B+\mu C=$ $\phi M+\alpha A$ : $\beta$ times $B$ and a $\mu$ times $C$ produce a compound color with $\phi$ times $M$ and $\alpha$ times $A$.

On Figure 2, the color located in the point $\boldsymbol{d}$ at the midway between $\boldsymbol{a}$ and $\boldsymbol{b}$ is produced by combining the same quantity of $\boldsymbol{a}$ and $\boldsymbol{b}$. If we add more amount or weight of, let us say, $\boldsymbol{a}$, then the center of gravity of the mixture would be closer to $\boldsymbol{a}$ in the spot where the support of the balance would have to be located in order to equilibrate the weights. If, for example, one wants to produce a new color $\boldsymbol{e}$ by adding amounts of the color $\boldsymbol{c}$ to the compound color $\boldsymbol{d}$, one 
traces the straight-line $\boldsymbol{d} \boldsymbol{c}$ and places the center of gravity depending on the amounts of color one adds of $\boldsymbol{c}$ and $\boldsymbol{d}$. Most of the compound color from $\boldsymbol{a}, \boldsymbol{b}$ and $\boldsymbol{c}$ are represented inside the triangle. With this same method, one can determine the location of every color that is left outside. If we wish to find the color $\boldsymbol{f}$ obtained by mixing $\boldsymbol{e}$ and a color $\boldsymbol{m}$ outside the triangle, we trace the segment $\boldsymbol{e m}$ and we follow the same steps. If the amount of $\boldsymbol{m}$ is very small, then the color $\boldsymbol{f}$ will still be inside the triangle. If the amount of $\boldsymbol{m}$ is increased little by little, we can establish the location of every combination that contain $\boldsymbol{m}$ on the segment $\mathbf{e m}$, the ones that are inside and also outside the triangle, as the case of the color $\boldsymbol{h}$.

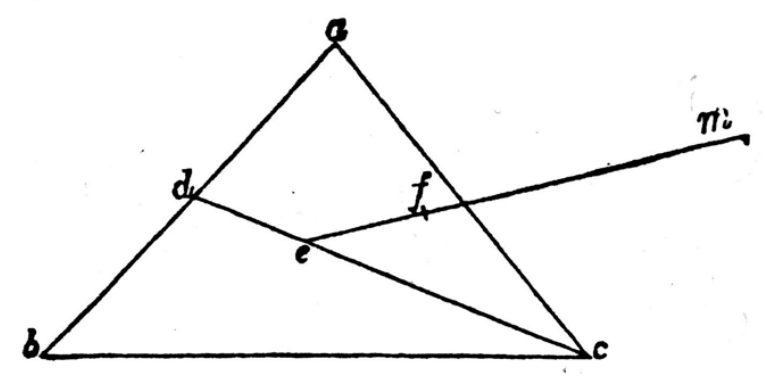

Figure 2. Color triangle ${ }^{18}$

When we take Newton's circle and insert the color triangle, we will be able to identify which colors are produced from the three primaries (Figure 3). In the figure, we can observe that most of the colors produced with violet $(V)$, red $(\mathrm{R})$, and green $(G)$ are located in the triangle $V R G$; the ones produced with cyan blue $(C)$, red $(R)$ and yellow $(Y)$ are found in the triangle RYC. At first, one might have the hope of having all saturated colors gathered on a circumference; if, moreover, all colors were situated at the same distance

${ }^{18}$ Helmholtz, 1860/1962, 134. 
from white, then white would have to be at the center of the circle. Once empirical information is gathered, we will find that the expectation of locating all saturated colors on a circumference and placing the color white at the center will have to be abandoned.

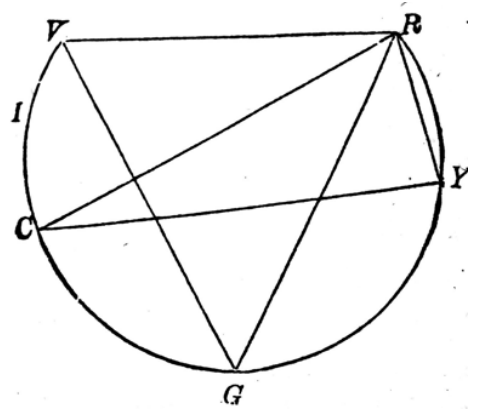

Figure 3. Color circle and color triangle ${ }^{19}$

Helmholtz choses violet, red and green as his primary colors in order to build his color chart. There is nothing in the colors of the spectrum that could hint which colors have to be primary; in that sense, the space can be constructed with three random colors with the condition that one cannot obtain a primary color by mixing the other two. The author picks those three motivated by the observations and discoveries regarding color blindness (for this could insinuate some preference for red and green) (Helmholtz, $1860 / 1962$, v. 2, 145). We have here, then, a mathematical instrument that gives us the rules for constructing a color chart with empirical information. To begin gathering information one must first clarify the concept of "weight" or "amount of color", and then one has to find how much it is

${ }^{19}$ Helmholtz, 1860/1962, v. 2, 142 
actually needed from each color in order to produce a particular mixture. Quoting Helmholtz,

Newton's device of exhibiting the laws of colour mixture by the method used for constructing centres of gravity was intended originally simply as a kind of mathematical picture for expressing graphically a large mass of facts; the justification for it consisting in the fact that the results as found by this process were qualitively in accordance with experimental realities, even if they had not been tested quantitatively. (Helmholtz, 1860/1962, v. 2,140$)$

With this in mind, Helmholtz postulates as a hypothesis a chart as the one exhibited in figure 4. In this figure, Newton's circle is distorted. The closed curve of saturated colors is no longer a circumference, and white is no longer placed at the same distance from every saturated color, since for obtaining white from, let us say, a yellowish green and violet, one needs a very small quantity of violet and bigger one from yellowish green. This would place the color white closer to yellow and farther from violet. Despite these differences, the main elements are preserved from Newton's instrument are preserved. 


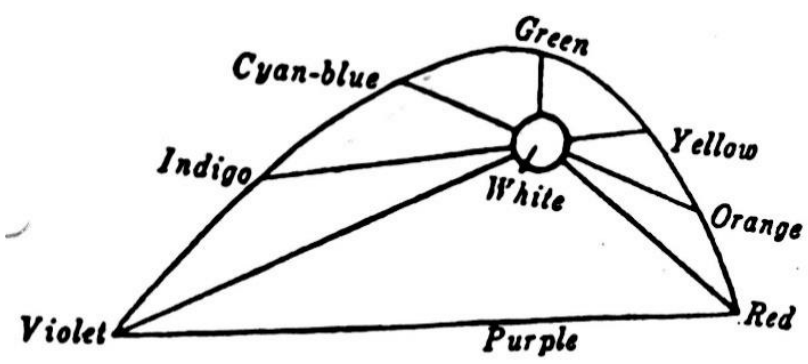

Figure 4. Helmholtz's color chart ${ }^{20}$

How do we shape this space with empirical information? The task is to determine the place where a particular color would be in this chart. To do this, it is necessary to identify how much "quantity" of each of the primary colors is needed to obtain the color we want. In that order of ideas, during the experiments, variables such as "quantity of color" must be controlled in a precise way, and additionally, one has to ask an observer in what moment he or she gets to see the color in question from a specific mixture. To achieve this, we require an experimenter manipulating the quantities of color $^{21}$, and an observer reporting the colors he or she sees.

Clerk Maxwell carried out this sort of experiments with color discs and with rays of homogenous light. Maxwell's primary colors were red, green and blue. For the purposes of the article, I will only present the experiments with color

${ }^{20}$ Helmholtz, 1860/1962, v. 2, 139.

${ }^{21}$ It is important to keep in mind that we are not talking about mixtures with pigments, but of mixtures with light rays or the light reflected by objects. 
discs. ${ }^{22}$ The experiment works in the following way (Figure 5). First, we make a disc with its center colored with the tone we want to produce; on the region surrounding the center, we assign areas to the colors we wish to combine. If we want to obtain a gray produced by an amount of black and white from the mixture of the three primary colors, the disc would have in its center a circle with a black area and a white area, and in the surrounding it would have a blue area, a red area and a green area. The amounts of each color can be modified, that is, one can decrease or increase the regions occupied by each color. Second, the experimenter makes the disc spin very fast in such a way that the observer sees not a disc with patches of colors, but a disc with its center and its outer ring as homogenously colored. Third, the experimenter asks the observer if he or she manages to discern between the color of the center (which could be different tones of gray) and the color of the surrounding (which could usually be reddish, greenish or blueish). If the observer still discerns between both areas of the circle, the experimenter has to keep modifying the amounts of color until the subject is unable to distinguish one color from the other and sees the disc as having only one color (i.e., some sort of gray).

22 Maxwell was aware of the disadvantages of doing the experiments with color discs because of absorption phenomena. For this reason, he developed sophisticated techniques to correct the effects produced by absorption (Maxwell, 1860, 65).

Manuscrito - Rev. Int. Fil. Campinas, v. 44, n. 1, pp. 37-97, Jan.-Mar. 2021. 


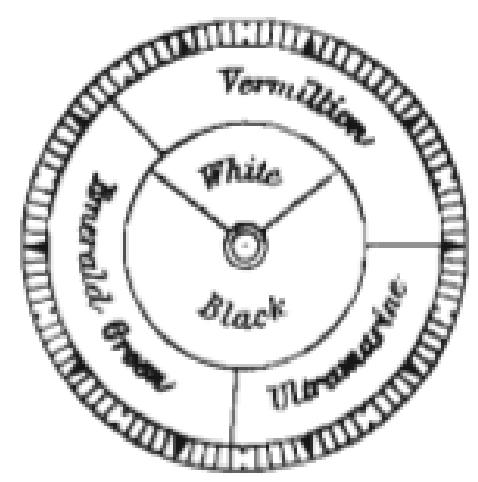

Figure 5. Maxwell's disc for the experiment ${ }^{23}$

Through this experiment, it is possible to obtain equations as the following:

$$
' 37 \mathrm{R}+' 27 \mathrm{U}+' 36 \mathrm{~V}=28 \mathrm{~B}+72 \mathrm{~N}
$$

The equation affirms that $37 \%$ of red, $27 \%$ of blue, and $36 \%$ of green produce a gray compounded by $28 \%$ of white and $72 \%$ of black. The experiment can be done with different colors at the center (orange, for example) and with the three primary colors in the outer ring, and then we ask the question: how much of green, red and blue one needs to produce this orange? When the observer does not discern between the two areas of the disc, the experimenter stops the disk and writes down the equation. From the information gathered, one starts to build the color space.

Now, given the fact that it is possible to make a color space of all observable colors from three primary colors, Helmholtz, in agreement with Thomas Young's suggestion

${ }^{23}$ Maxwell, 1855, 299. 
(1802), adventures to follow a physiological hypothesis for color vision [the three-receptor theory]: we can assume that in our retinas we have three different sort of fibers, each one of them particularly sensible to a determinate range of wavelengths corresponding the ones that produce red, the ones that produce green and the ones that produce violet (Helmholtz, 1860, 1962, v. 2, 143-144). "When we speak of reducing the colours to three fundamental colours, this must be understood in a subjective sense and as being an attempt to trace the colour sensations to three fundamental sensations." (Helmholtz, 1962, v. 2, 143). Let us assume that prismatic colors are laid out in a horizontal line in the same manner as they appear in the spectrum (Figure 6): curve 1 represents the degree of excitement of the fibers mainly sensible to red; curve 2 indicates the degree of excitement of the fibers mainly sensible to green; and curve 3 shows the degree of excitement of the fibers sensible mainly to violet. ${ }^{24}$ The curves exhibited in Figure 6 were suggested by Helmholtz as a hypothesis; these can be empirically determined with experiments such as Maxwell's: for instance, the color placed in $O$ can be analyzed in three components: the amount of red indicated in curve 1 , the amount of green indicated in curve 2 , and the amount of blue indicated in curve 3 . In that sense, when we observe this particular orange, the redsensible fibers are the ones that are more excited, the greensensible fibers are less excited and, finally, the blue-sensible fibers would be the least excited.

${ }^{24}$ By "mainly sensible" I mean that each fiber does not respond solely to one type of light; they are sensible to all sorts of light but have a peak of sensibility associated to a specific color.

Manuscrito - Rev. Int. Fil. Campinas, v. 44, n. 1, pp. 37-97, Jan.-Mar. 2021. 


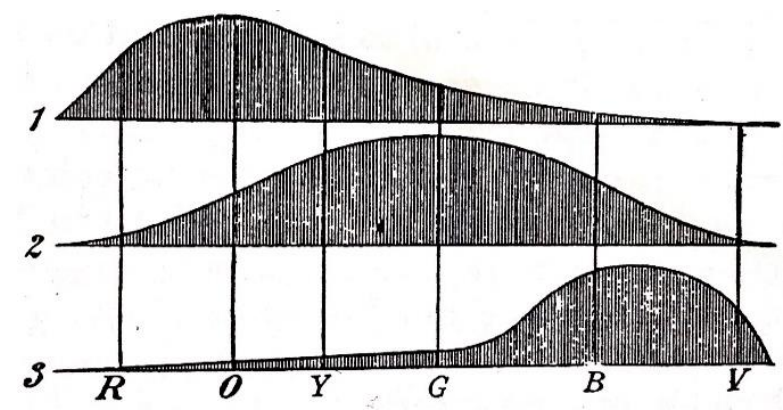

Figure 6. Degree of excitement of the three types of fibers in the retina ${ }^{25}$

With this hypothesis, Helmhotlz manages to explain our sensation of all colors: all of them can be conceived as the combination of the sensations produced in the different types of fibers.

Pure red light stimulates the red-sensitive fibres strongly and the two other kinds of fibres feebly; giving the sensation red.

Pure yellow light stimulates the red-sensitive and the green-sensitive fibres moderately and the violet-sensitive fibres feebly; giving the sensation yellow.

Pure green light stimulates the green-sensitive fibres strongly and the two other kinds much more feebly; giving the sensation green.

Pure blue light stimulates the green-sensitive and the violet sensitive fibres moderately, and the red-sensitive fibres feebly; giving the sensation blue.

${ }^{25}$ Helmholtz, 1860/1962, v. 2, 143. 
Pure violet light stimulates the violet-sensitive fibres strongly, and the other fibres feebly; giving the sensation violet.

When all the fibres are stimulated about equally, the sensation is that of white or pale hues. (Helmholtz, 1860/1962, v. 2, 144)

To recapitulate, Helmholtz's investigation has three moments. First, he begins with a mathematical model proposed by Newton. This instrument invites us to imagine colors as being placed at each end of a balance. Colors are then assigned weights, and the balance is at equilibrium when its fulcrum is placed at the center of gravity of the two "masses" of color. With the modifications made by Grassmann, the construction of the color space works in the following way: one builds a space whose components are color-points. The space can be configurated by taking three points as its basis, as long as they are not collinear. All colors in this Grassmaninan space can be analyzed in the three "primary" colors that we have chosen as basic; in other words, any color we like can be described as a lineal combination of the three basic colors. This is equivalent to Newton's balance metaphor.

Second, the author devised experimental settings (such as Maxwell's experiments) in order to build a color chart. Third, given that with the mathematical model and empirical information it is possible to draw a map of all colors with only three variables or primary colors, this sets out the path for stating that in the retina exist three types of receptors, each of them mainly sensitive to a different primary color, i.e., red, green and violet. According to this description, Helmholtz's investigation harmonically combines two styles: an analogical style (the use of Newton's instrument with Grassmann's improvements), and an experimental style (the use 
of empirical information collected through Maxwell's experiments where the variables of the model are controlled).

In addition, Helmholtz's hypotheses demand mechanisms compatible with the laws of the physical and chemical theories of the time. Indeed, the three fibers posited by the scientist are simply stimulated in different degrees by an external cause (i.e. light rays of different wavelengths), they have particular features that determine the quality of the sensations aroused by external causes, and they do not demand any additional activity of the organism outside the scope of these mechanisms. As we will see, Helmholtz's physiological correlate for color sensation differs from Hering's hypothesis.

\section{Ewald Hering}

Just as Helmholtz, Hering builds a color chart and suggests a physiological hypothesis. However, Hering moves away from Helmholtz in crucial aspects. On the one hand, Hering doesn't begin with a previous model to structure the phenomenon. It will be the phenomenon itself the one that will indicate its structure and the variables in play. On the other hand, the physical nature of light is ignored; for him, the nature of light is irrelevant for understanding the sort of processes occurring in our sense organs responsible for color vision. Focusing on light (as once others focused on pigments) is concentrating on an external cause and not on the object of study, that is, the physiological processes in our eyes that produce the contemplation of a color in our consciousness: "one should not permit the means and the methods by which a color is produced to influence the judgments of colors as such." (Hering, 1872/1964, 49). In 
Hering's opinion, the physiologist must begin his investigation analyzing color as a visual quality, that is, as a phenomenological approach. What he has to do is to study the phenomenological variables of color sensation and, from there, infer the possible physiological correlate that has to exist in order for such an experience to be possible.

What we want is to classify the great multiplicity of colors to get a systematic perspective of them, and designations for them such that the reader is given a comprehensible expression as precise as possible for every color, so that he can mentally reproduce any color with some exactness. To do this we must at first disregard altogether the causes and conditions of their arousal. For a systematic grouping of colors the only thing that matters is color itself. (Hering, 1872/1964, 25; emphasis of my own).

Hering is allowed to have this starting point because of the following heuristic rule: the phenomena of consciousness can be regarded as a mirror of the physiological mechanisms in our sense organs; hence, the task is to make a physiological psychology or, better yet, a physiology of consciousness. (Hering, 1897). In his own words: "vision, as a psychological event, is always accompanied by a physical event in the neural substance of the inner eye, and [...] corresponding to every color there is a specific neural activity which we can designate as the somatic correlate of the color." (Hering, 1872/1964, 21. Emphasis of my own). Hering proceeds "on the assumption that every color is lawfully related to a quite specific process in the nervous substance in the sensory system. For without the assumption of such a lawful relation, it would be useless to make sensory phenomena the subject of physiological 
study." (Hering, 1872/1964, 106). With this in mind, the author sets out to identify the phenomenological variables present in color vision and their relations in order to build a color space with these variables: the task is to "ascertain with regard to the multiplicity of colors [as visual qualities] whether any, and which, variables can be determined in them.” (Hering, 1872/1964, 24).

The first thing the author does is to identify that colors can be divided into chromatic colors (the colors of the physical spectrum) and achromatic colors (black, white and the scale of grays). Achromatic colors can be described with two opposite variables, i.e. black and white. Any color in the middle can be decomposed into particular amounts of black and white. Hence, these colors can be portrayed in a series with white and black at each end. The place of every intermediate gray can be determined if one specifies the percentage of black and white for each one (Figure 7).

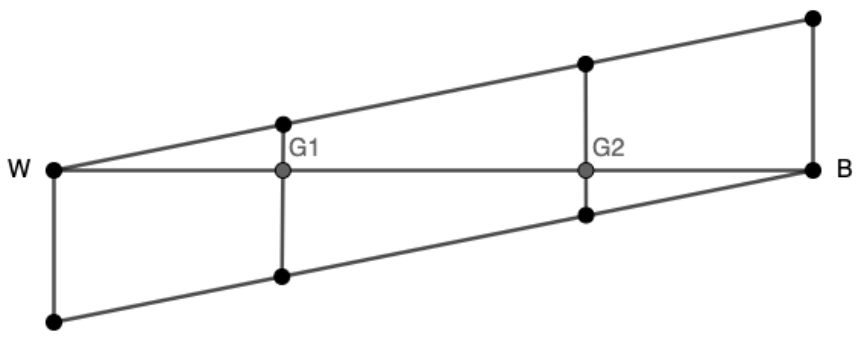

Figure 7. Series of achromatic colors ${ }^{26}$

Chromatic colors, according to Hering, can be described with at least four variables: red, green, yellow and blue. To justify the priority of these four colors, Hering gives the following arguments. Let us imagine that chromatic colors

${ }^{26}$ Hering, 1872/1964, 35. 
are represented in a circle in such a way that there's the least difference between neighboring colors (Figure 8). If we observe the circle starting with red, we can see that red slowly becomes yellowish until, finally, we encounter a pure yellow with no traces of red. If we continue, we will see that yellow slowly turns greenish until we find a pure green with no traces of yellow; green then gradually begins to look bluish until we get to a pure blue with no hints of green; finally, blue turns reddish until we arrive at the point where we had started, that is, a pure red with no hints of blue. With this observation, Hering finds it clear that we can describe all colors with red, green, yellow and blue. (Hering, 1872/1964, 42). In addition, Hering justifies the primacy of these colors stating that if we cut the circle passing through two primary colors, e.g. yellow and blue, one half of the circle will contain the series of colors that share the visual quality of red and the other half will contain the series of colors that share the visual quality of green. The same happens if we cut the circle through red and green: one half will have all colors sharing blue and the other half would have all colors sharing yellow. However, this would not happen if we cut the circle passing through another pair of colors; in other words, each half would not have a series of colors sharing one visual quality. (Hering, 1872/1964, 43). 


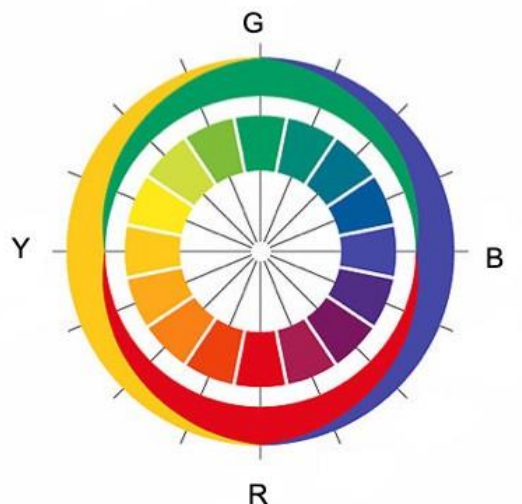

Figure 8. Circle of chromatic colors ${ }^{27}$

Furthermore, Hering claims that colors are organized as pair of opposites: green-red and yellow-blue. According to the author, it is not possible to cut the circle in half passing through the primary colors and then describe the series in each hemisphere in terms of the two colors at each end, for each series of colors would only have one chromatic property in common. If we cut through blue and yellow, each half would share only one property, either red or green, but none of the colors would share both blue and yellow. The same occurs if we divide the circle passing through red and green. Therefore, it is not possible to describe a color as bluish yellow or reddish green. Thus, the color circle can be considered as divided in quadrants, each of them containing a series of chromatic colors that can be described with two variables (the red-yellow colors, the yellow-green colors, the green-blue colors, and the blue-red colors).

Added to the chromatic color circle and the series of achromatic colors, Hering tells us that chromatic colors can

${ }^{27}$ Hering 1872/1964, 49 
also be veiled, that is, they can be mixed with white, black or gray. Veiled colors can be represented in a triangle where one of the vertices is a chromatic color (e.g. red), and the other two white and black (Figure 9). (Hering, 1872/1964, 51). If we put together the triangle of veiled colors, the color circle and the series of achromatic colors, we obtain a color space as the one exhibited in Figure 10.

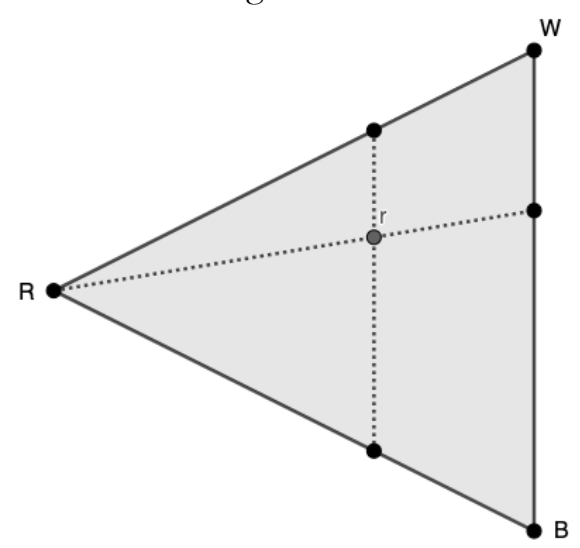

Figure 9. Triangle of veiled colors ${ }^{28}$

${ }^{28}$ Hering, 1872/1964, 51

Manuscrito - Rev. Int. Fil. Campinas, v. 44, n. 1, pp. 37-97, Jan.-Mar. 2021. 


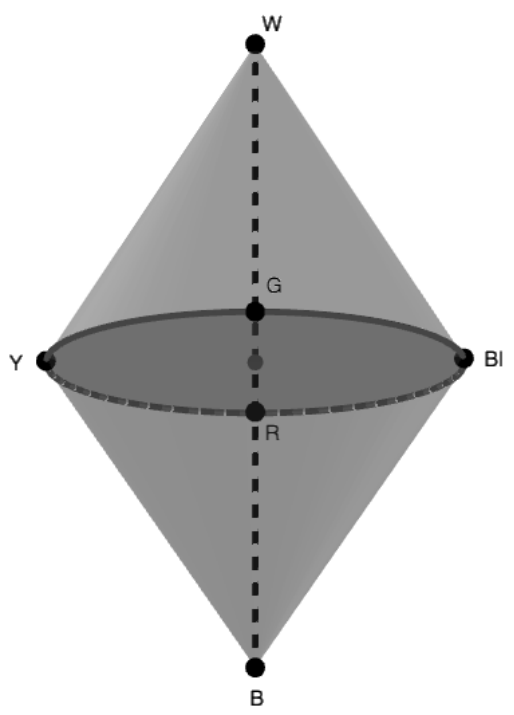

Figure 10. Hering's color space

According to Hering, the color space is constructed from variables that are purely phenomenological. With the six colors black, white, red, green, yellow and blue it is possible to describe all observable colors. In that sense, if we tell someone to conceive a greenish yellow veiled with white, that person could imagine it. Moreover, Hering's chart forbids descriptions such as "reddish green" or "yellowish blue", for precisely these colors are unconceivable for anyone. For this reason, the variables are organized as pairs of opposites: black-white, red-green and yellow-blue. ${ }^{29}$

${ }^{29}$ One might say that a color being "unconceivable" is something psychological, not physiological. If Hering is doing physiology, why is his psychological/phenomenological aspect important? For Hering, the fact that one has not seen a reddish green or a yellowish blue, or that one cannot imagine such a color, must be an expression of the way in which colors appear to us and, 
After building his color space, the author follows the heuristic rule quoted above, and states his physiological hypothesis: if phenomenologically speaking we identify six variables organized as pairs of opposite colors, then in our sense organs there must be three mechanisms, each one of them corresponding to an antagonism relationship [the opponent-process theory]. These mechanisms consist on processes of assimilation and dissimilation, which are controlled by the self-regulation and reciprocal interaction in our retinas; the latter are usually triggered by external stimulus (Hering, 1872/1964, 107-113, 173). The colors we experience coincide with the ratios of the antagonistic processes that are carried out in our visual system. Hering sees these processes as constitutive and present in any form of life. In his opinion, in every vital phenomenon one sees cases where organisms apprehend something and turn it into a part of themselves, and cases where organisms dismiss or separate from substances that they consider alien. ${ }^{30}$ Hering assumes that assimilation and dissimilation are inseparable, and they "must rather be conceived as two closely interwoven processes, which constitute the metabolism (unknown to us in its intrinsic nature) of the living substance, and are active in its smallest particles." (Hering, 1888/1897,

furthermore, an expression of an underlying physiological process (Hering, 1872/1964, 47, 50).

${ }^{30}$ Hering's proposal has family resemblances with Goethe's theory: "Thus, inspiration already presupposes expiration; thus every systole its diastole. It is the universal formula of life which manifests itself in this as in all other cases. When darkness is presented to the eye, it demands brightness, and vice versa: it shows its vital energy, its fitness to receive the impression of the object, precisely by spontaneously tending to an opposite state." (Goethe, 1818/2006, \$38).

Manuscrito - Rev. Int. Fil. Campinas, v. 44, n. 1, pp. 37-97, Jan.-Mar. 2021. 
232). For Hering: "If it is assumed that this metabolic activity of the living visual substance is the somatic correlate of the colors of the visual field, the possibility arises of assembling a profusion of facts that have been collected, up to now, without any integration, under a unitary, comprehensive point of view[...].” (Hering, 1872/1964, 107).

For the case of achromatic colors, the processes of assimilation, dissimilation, self-regulation and reciprocal interaction of the retina work in the following way. Let us imagine that an observer receives a stimulus that triggers dissimilation [D-stimulus] and that produces the impression of some sort of white. Given that every living substance has the ability to return to its previous state with self-regulation, after this stimulus, the organism's disposition for the antagonistic process will be higher. Hence, if we remove the D-stimulus, the observer will have a greater disposition for assimilation, in other words, his/her A-disposition or $A$ excitability will increase. In addition, a stimulus not only affects the portion it is directly acting on. If a portion of the retina is stimulated and triggers an assimilation process $(A>D)$ or a dissimilation process $(D>A)$, this induces the surroundings of the stimulated area to an increase in the antagonistic process and a decrease in the other one, all of this in order to maintain a balance in all the somatic field (Hering, 1872/1964, 173). In his words,

The author offered many experimental settings as the one shown in Figure 11 to support his hypothesis. On the left, we have a source of light $l$ that illuminates a white wall in front of it; we have another source of light $L$ that is blocked with a sheet of black paper, and in addition, there is a black spot that represents a black object. The observer is located in front of this wall and observes the wall as being illuminated by an amount of light $l$. In the situation on the 
right, the sheet of black paper is removed, and the source of light $L$ is unblocked. In this case, some areas on the wall will more illuminated $(l+L)$, and the area with object's shadow will be illuminated only by $l$. The interesting thing about the experiment is that the observer when passing from one situation to the other, reports what he sees no as an increase of light in the other areas, but as a darkening of the shadowed area. For Hering, this is proof of the reciprocal interaction in the areas of the retina and the processes of self-regulation. Indeed, " $[\ldots]$ an increase or decrease in the illumination affecting only a part of the retina not only produces an increased or decreased brightness in the corresponding part of the psychological visual field, but also at the same time causes an opposite change in brightness in the rest of the visual field." (Hering, 1872/1964, 219).

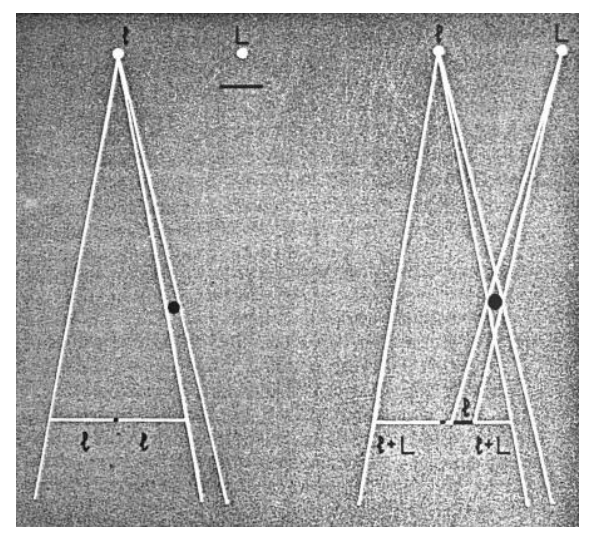

Figure 11. Experiment for the reciprocal interaction of the retina $^{31}$

${ }^{31}$ Hering, 1872/1964, 220

Manuscrito - Rev. Int. Fil. Campinas, v. 44, n. 1, pp. 37-97, Jan.-Mar. 2021. 
Concerning chromatic colors, the relations of opposition are explained differently. Hering assigns valences to different light rays depending not on its wavelength, but on the type of chromatic sensation that they produce. Hence, if a light produces the contemplation of blue, it would have a blue valence, and in our visual system a blue-generating force would be triggered (Hering, 1872/1964, 307). Keeping this in mind, we can imagine this experimental approach: if we first stimulate an observer with a light with yellow valence, and then we submit the observer to a different stimulus that slowly takes away the "yellowness" of the color until it turns into white, "then we can say that the previously yellowproducing light in the illuminated region of the somatic visual field had called up a force antagonistic to the yellow valence of the light, through which the yellow-producing force is canceled or neutralized." (Hering, 1872/1964, 307). If we maintain this last stimulus and the color white starts turning blue, then we can say that "the opposing force aroused in the illuminated region of the living substance has now gained dominance over the yellow producing force of the light, and that it is a blue-producing one." (Hering, 1872/964, 307). ${ }^{32}$ Hering did not go through with the experiments, probably because he did not have the instruments needed. However, he did give us hints on how to do it.

The works of Hurvich and Jameson (1955) in the mid of the $20^{\text {th }}$ century show us that one can set out precise experimental conditions to support Hering's ideas:

The experimental approach permitting differentiation of the various chromatic

\footnotetext{
32 These visual processes seem more complex than the account of Helmholtz's theory. However, for Hering, this opposition was just as basic as Helmholtz's three fundamental sensations.
}

Manuscrito - Rev. Int. Fil. Campinas, v. 44, n. 1, pp. 37-97, Jan.-Mar. 2021. 
responses per se is implicit in the Hering opponent-colors theory. [...] A yellow response of given magnitude should be exactly canceled by a stimulus that elicits the same magnitude of blue response, and a similar relation should hold between red and green responses. This view leads directly to an experimental approach in which a null method can be used to measure the spectral distributions of the separate chromatic responses. (Hurvich \& Jameson, 1955, 547548)

Figure 12 exhibits the instrument used by the two authors in their investigations. To do the experiments, one first needs an observer that is stimulated by a light that elicits a determinate hue, let us say, an orange. The task is to identify how much of red is in this orange, and to do this, one stimulates the observer with a light that elicits the opponent color of red, that is, green. Now, given that the observer cannot see a greenish orange, what she sees is an orange that begins to lose its redness. When the observer reports that the red is gone, and that she is contemplating a whitish yellow without any green either, one can determine that the amount of green used to cancel red indicates the amount of red in the initial orange. This method is repeated with every color of the spectrum and, finally, one obtains a chart as the one in Figure 13.33

\footnotetext{
${ }^{33}$ Hurvich and Jameson, by convention, decided to assign positive and negative valences in order to build this chart.
} 


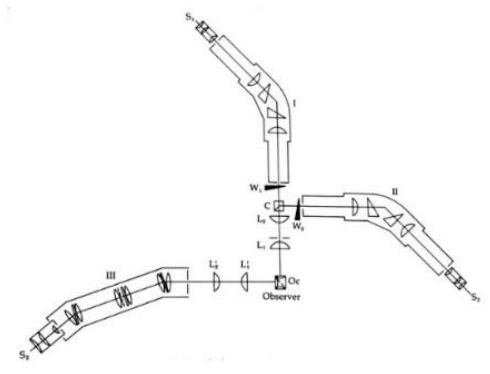

Figure 12. Instrument used in Hurvich and Jameson's experiment ${ }^{34}$

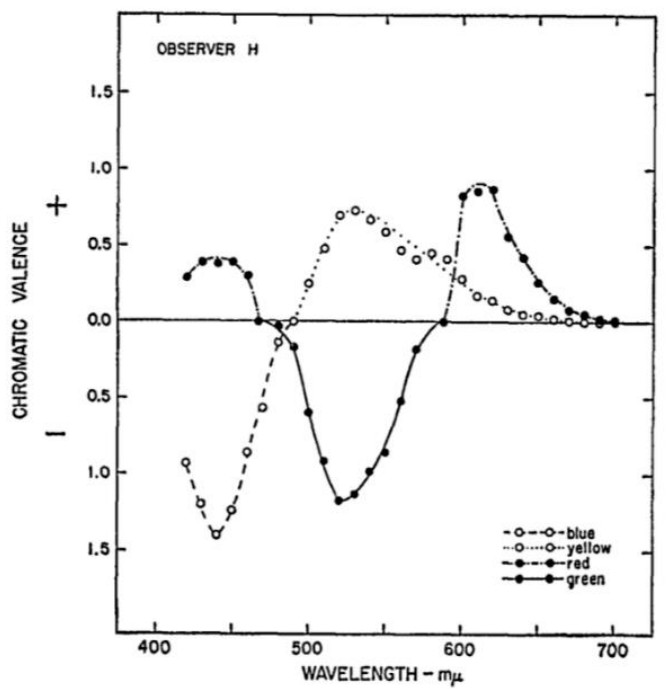

Figure 13. Chromatic responses ${ }^{35}$

${ }^{34}$ Hurvich \& Jameson, 1955, 548

35 Hurvich \& Jameson, 1955, 550

Manuscrito - Rev. Int. Fil. Campinas, v. 44, n. 1, pp. 37-97, Jan.-Mar. 2021. 
Keeping in mind what has been said regarding Hering's investigation, one can see that Hering does follow an experimental style; nevertheless, he does not use an analogical style. The author does not begin with a previous model to structure the phenomenon, identify the variables, and build a color space. It is color itself, as a visual quality, the one that sets up the guideline for the investigator and the one that determines which physiological hypothesis is viable. Hering's hypothesis may be odd or incompatible with the physical and chemical theories of the time. In Helmholtz own words for describing theories such as Hering's, "these explanations attribute forms of activity to the nervous substance such as may perhaps be found in the region of the lower psychic activities, but nothing similar to which has never been discovered in the domain of inorganic nature." (Helmholtz, 1866/1962, 546). Indeed, Hering always proceeded by following his maxim, i.e., that the phenomena of consciousness are a mirror of the physiological mechanisms in our sense organs.

\section{Conclusion}

In the previous section, I presented the authors' theories and the methods they used in their investigation on color sensation. I have shown that both of them use an experimental style, but that only Helmholtz uses an analogical style. This difference led to completely different theories. Now, as I had said before, I think their stylistic differences were an expression of deep tensions in their presuppositions regarding the nature of the phenomenon under study.

Both authors embraced the experimental approach to physiology during the $19^{\text {th }}$ century. Even though both of 
them welcomed the experimental rigor, Helmholtz also adopted the models and the methods of mathematics, physics and chemistry, while Hering claimed the autonomy of vital phenomena. In Turner's words:

The researchers upon whom Helmholtz drew predominantly in his great synthesis [on color vision] [...] were physicists. The methods Helmholtz borrowed from these men and made de rigueur for color vision studies henceforth were physical methods. [...] [Helmholtz] was ideally suited to create a tradition of color vision research that would integrate the methodological approaches of the physicist and the physiologist, or -as Ewald Hering and his followers were soon to claimto subordinate physiological to physical understanding altogether. (Turner, 1994, 114)

Contrary to this view, Hering believed it was necessary to put all our physical knowledge of the world on hold and focus solely on color itself. For him,

up to now investigations of the light sense had to be pretty much restricted to establishing the rules by which the colors appearing in the visual field depend on the nature of light rays that impinge on the retina $[\ldots]$ and from these rules to draw tentative conclusions about the significance of the changes so far known to be brought about in the visual tissue by light. (Hering, 1872/1964, 24. Emphasis of my own)

Nevertheless, the study of color vision had to begin with the study of "all the distinguishable properties of colors or 
visual qualities" (Hering, 1872/1964, 24). According to Hering, these fundamental phenomenological properties (or variables) had to be accompanied by physiological processes. Thus, he considered that with the study of the internal structure of color, it would be possible to hypothesize the behavior and structure of the underlying physiological mechanisms -even if those mechanisms themselves were still left unexplained (Hering, 1872/1964, 176).

In a sense, Hering's color studies were closer to the romantic tradition that the experimental physiology intended to overcome. Concerning Goethe and Newton's dispute over color and Goethe's scientific methodology, Helmholtz uses the following words:

Goethe, though he exercised his powers in many spheres of intellectual activity, is nevertheless, par excellence, a poet. Now in poetry, as in every other art, the essential thing is to make the material of the art, be it words, or music, or colour, the direct vehicle of an idea. In a perfect work of art, the idea must be present and dominate the whole, almost unknown to the poet himself, not as a result of a long intellectual process, but as inspired by a direct intuition of the inner eye [...]. Instead of trying to arrange the phenomena of nature under definite conceptions, independent of intuition, he sits down to contemplate them as he would a work of art, complete in itself, and certain to yield up its central idea, sooner or later, to a sufficiently susceptible student. [...] Thus, in the theory of colour, Goethe remains faithful to his principle, that Nature must reveal her secrets of her own free will [...]. 
Accordingly, he demands as a preliminary to the investigation of physical phenomenon that the observed facts shall be so arranged that one explains the other [...]. (Helmholtz, 1853/1995, 8-9, 12).

In contrast, a scientist closer to Newton's way of doing science would see its object of study very differently:

A natural phenomenon is not considered in physical science to be fully explained until you have traced it back to the ultimate forces which are concerned in its production and its maintenance. Now, as we can never become cognizant of forces qua forces, but only of their effects, we are compelled in every explanation of natural phenomena to leave the sphere of sense, and to pass to things which are not objects of sense, and are defined only by abstract conceptions. [...] But this step into the region of abstract conceptions, which must necessarily be taken, if we wish to penetrate to the causes of phenomena, scares the poet away. To [the natural philosopher] the impressions of sense are not an irrefragable authority; he examines what claim they have to be trusted; he asks whether things which they pronounce alike are really alike, and whether things which they pronounce different are really different; and often finds that he must answer, no! (Helmholtz, 1853/1995, 12-13).

In my opinion, Helmholtz and Hering drifted apart in a matter similar to Newton and Goethe's. Both of them thought differently on how their phenomenon had to be 
studied, what they could rightly say about it, and how they could justify it. In other words, the two of them embraced different styles.

Helmholtz's starting points -in addition to Müller's law (De Kock, 2014)- were the models offered by mathematicians, physicists and chemists. Given that observation for itself cannot reveal us the causes and explanations that a scientist is looking for, it is necessary to turn to theories and instruments previously conceived in order to organize the natural phenomena we wish to understand. This is what the author does when he adopts Newton's and Grassmann's instrument, and when he posits physiological processes that remain in agreement with physical theories. Everything that goes beyond this realm and has a mental or psychological feature [perception] must be studied as a psychological fact developed from experience and training (Helmholtz, 1866/1962, v. 3, 1). Scientists, according to Helmholtz, must, above all things, seek to explain all physical phenomena with the laws of physics. And organisms, even though they are living substances, are still physical substances that must obey physical laws. In other words, Helmholtz has on his horizon the goal of the unity of science:

Each individual fact, taken of itself, can indeed arouse our curiosity or our astonishment, or be useful for us in its practical applications. But intellectual satisfaction we obtain only from a connection of the whole, just form its conformity with law. [...]. There is a kind, I might almost say, of artistic satisfaction, when we are able to survey the enormous wealth of nature as a regularlyordered whole - a kosmos, an image of the 
logical thought of our own mind. (Helmholtz, 1862/1995, 97. Emphasis of my own).

In Helmholtz opinion, Hering's hypotheses were ascribing psychic properties to the body, which is, and should behave, as a physical object. (Helmholtz, 1866/1962, v. 3, 531): "Physiologists, then, must expect to meet with an unconditional conformity to law of the forces of nature in their inquiries respecting the vital processes; they will have to apply themselves to the investigation of the physical and chemical processes going on within the organism." (Helmholtz, 1869/1995, 217).

Contrary to this view, Hering's stance on the physical approach to vital phenomena was the following:

In fact, life is still as much of an unsolved riddle as it was when the so-called mechanical conception of vital phenomena overthrew the vitalistic. $[. .$.$] The impulse to resort to analogy$ and to carry over propositions abstracted from one domain into others is so great that there can be no fear that any phenomenon of life will long remain exempt from physical or chemical explanation after physics and chemistry have supplied the requisite means. (Hering, 1900, 168-170. Emphasis of my own)

Hering's invitation is to change our point of view (Hering, 1897, 4), for by adopting Helmholtz's analogical style, we start focusing on categories and concepts conceived for 
other domains, and we overpass what we wanted to study in the first place. Life demands categories of its own. ${ }^{36}$

It was probably these deep differences between the two authors that guided their styles of reasoning and kept them from arriving at consensus regarding their theories of color sensation. Helmholtz agreed with using models and tools taken from other fields and disciplines in order to understand physiological phenomena. He hoped for a unity in the explanation of all physical phenomena -organic and inorganic-. Hering, on the contrary, stood up for the autonomy of physiological research with respect to other sciences. Maybe it was these fundamental assumptions the ones that guided the questions and the explanations given by each one of them, and the ones that possibly played a crucial role in their stylistic decisions. ${ }^{37} \mathrm{I}$ do not want to claim that the framing I have offered in terms of "styles of reasoning" is the only possible depiction for this particular case of the

${ }^{36}$ It seems, then, that the tensions regarding the physiological mechanisms of color sensation can be traced back to the controversies regarding materialism and vitalism during the $19^{\text {th }}$ century. However, this is a matter for a different paper.

${ }^{37}$ During the first 50 years of the 20th century, the scientific community ruled in favor of Helmholtz's theory. Probably because Helmholtz's importance and influence in the scientific field were much greater than Hering's (Hurvich, 1969). It was not until the works of Hurvich and Jameson and also the experiments of DeValois and Jones (1961) that the scientific community began to reconsider Hering's ideas. DeValois and Jones found empirical evidence both for Helmholtz's three-receptor theory and Hering's opponent-process theory in primates in different layers of the retina; and Hurvich and Jameson offered a procedure for a mathematical and quantitative control that Hering had failed to offer. 
controversy. However, it might be illuminating for understanding other features of the debate.

\section{References}

Cahan, David. Hermann von Helmboltz and the Foundations of Nineteenth Century Science, Berkeley: University of California Press, 1993.

Cranefield, Paul F. "The Organic Physics of 1847 and the Biophysics of Today". Journal of the history of medicine and allied sciences, 12, pp. 407-423, 1957.

Crombie, Alistair C. Styles of Scientific Thinking in the European Tradition: The History of Argument and Explanation specially in the Mathematical and Biomedical Sciences and Arts. Londres: Gerald Duckworth \& Company, 1994.

Cunningham, Andrew and Jardine, Nicholas. Romanticism and the Sciences. Cambridge: Cambridge University Press, 1990.

DeKcok, Liesbet. "Hermann von Helmholtz's EmpiricoTranscendentalism Reconsidered: Construction and Constitution in Helmholtz's Psychology of the Object”. Science in Context, 27(4), p. 709-744, 2014.

DeValois, R. L. \& Jones, A. E. "Single-Cell Analysis of the Organization of the Primate Color-Vision System". In Richard Jung and Franz Kornhuber (eds.), 1961, pp. 178-191.

Fechner, Gustav Theodore. The little book of life and death. Trans. by Mary. C. Wadsworth, Boston: Weiser Books, 1836/2005. 
Fleck, Ludwik. Genesis and Development of a Scientific Fact. Trans. by Frederick Bradley and Thaddeus J. Trenn, Chicago: Chicago University Press, 1935/1979.

Grassmann, Hermann. "On the Theory of Compound Colours". Philosophical Magazine, Series 4, 7(45), p. 254264, 1854.

Goethe, Johann Wolfang. Theory of Colours. Trans. by Charles Lock Eastlake, London: John Murray, 1840. Repr. in New York: Dover Publications, Inc., 1810/2006.

Hacking, Ian. "Language, Truth and Reason". In Martin Hollis and Steven Lukes (eds.), 1982, pp. 48-66.

Hacking, Ian. "Style for historians and philosophers". Studies in History and Philosophy of Science, 23(1), pp. 1-20, 1992a.

Hacking, Ian. "Statistical Language, Statistical Truth, and Stadistical Reason: The Self-Authentification of a Style of Scientific Reasoning". In Ernan McMullin (ed.), 1992b, pp. 130-157.

Heidelberger, Michael. Nature from within: Gustav Fechner and his vision psychophysical worldview, Pittsburg: University of Pittsburg Press, 1993a.

Heidelberger, Michael. "Force, Law and Experiment. The evolution of Helmholtz's Philosophy of Science". In David Cahan (ed.), pp. 461-497, 1993b.

Hermann von Helmholtz. Treatise on Physiological Optics, Vol. 1 (1855), Vol. 2 (1860), Vol. 3 (1866). Trans. James P. Cocke, Mineola (New York): Dover Publications Inc, 1962 and repr. 2005. 
Helmholtz, Hermann von. "On Goethe's Scientific Researches". Trans. by E. Atkinson, New York: D. Appleton and Company, 1853/1873. Repr. in Hermann von Helmholtz, 1995, pp. 1-17.

Helmholtz, Hermann von. Ueber das Sehen des Menschen: Ein popular Wissenschaftlicher Vortrag. Leipzig: Leopold Voss, 1855.

Helmholtz, Hermann von. "On the Conservation of Force". Trans. by E. Atkinson, New York: D. Appleton and Company, 1862/1873. Repr. in Hermann von Helmholtz, 1995, pp. 96-126.

Helmholtz, Hermann von. "The Recent Progress of the Theory of Vision". Trans. by E. Atkinson, New York: D. Appleton and Company, 1868/1873. Repr. in Hermann von Helmholtz, 1995, 127-203.

Helmholtz, Hermann von. "On the Aim and Progress of Physical Science". Trans. by E. Atkinson, New York:

D. Appleton and Company, 1869/1873. Repr. in Hermann von Helmholtz, 1995, pp. 204-225.

Helmholtz, Hermann von (1877/1995). "On Thought in Medicine". Trans. by E. Atkinson, New York: Longmans, Green and Company, 1877/1893. Repr. in Hermann von Helmholtz, 1995, pp. 309-327.

Helmholtz, Hermann von. "The Facts of Perception". Trans. by David Cahan. In Hermann von Helmholtz, 1878/1995, pp. 342-380.

Helmholtz, Hermann von. Science and Culture: Popular and Philosophical Essays. David Cahan (ed.), Chicago: The Univesity of Chicago Press, 1995. 
Hering, Ewald. Outlines of a theory of light sense. Trans. by Leo M. Hurvich and Dorothea Jameson, Cambridge (Mass): Harvard University Press, 1872/1964.

Hering, Ewald. Zur Lehre vom Lichtsinne. Sechs Mittheilungen an die kaiserl. Akademie der Wissenshaften in Wien. Viena: Druck und Verlag von Carl Gerold's Sohn, 1878.

Hering, Ewald. "Theory of the Functions in Living Matter". Trans. by F. A. Welby. Brain, 20(1-2), pp. 232-258, $1888 / 1897$.

Hering, Ewald. On Memory and the Specific Energies of the Nerveus System. Chicago: The Open Court Publishing Company, 1897.

Hering, Ewald. "On the theory of nerve activity". The Monist, 10(2), pp. 167-187, 1900.

Hollis, Martin and Lukes, Steven. Rationality and Relativism. Cambridge (Mass): The MIT Press, 1982.

Hurvich, Leo M \& Jameson, Dorothea. "Some Quantitative Aspects of an Opponent-Colors Theory: I. Chromatic Responses and Spectral Saturation". Journal of the optical society of America, 45(7), pp. 546-552, 1955.

Hurvich, Leo M \& Jameson, Dorothea. "Introduction". In Ewald Hering, 1872/1964, pp. vii-xvii.

Hurvich, Leo M. "Hering and the scientific establishment. American Psychologist, 24(5), pp. 497-514, 1969.

Jung, Richard and Kornhuber, Franz. The Visual System: Neurophysiology and Psychophysics. Berlín: Springer, 1961.

Knight, David. "Romanticism and the sciences". In Andrew Cunningham \& Nicholas Jardine (eds.), 1990, pp. 1324. 
Kremer, Richard L. "Innovation Through Syhtesis: Helmholtz and Color Research". In David Cahan (ed.), 1993, pp. 205-258.

Maxwell, J. C. "Experiments on colour as perceived by the eye." Transactions of the Royal Society of Edinburgh, 21(2), pp. 275-298, 1855.

Maxwell, J. C. "On the Theory of Compound Colours, and the Relations of the Colours of the Spectrum". Philosophical Transactions of the Royal Society of London, 150, pp. 57-84, 1860.

McMullin, Ernan. The Social Dimensions of Science. Notre Dame (Ind): University of Notre Dame Press, 1992b.

Müller, Johannes. Elements of Physiology. Trans. by W. Baly, Philadelphia: Lea and Blanchard, 1843.

Newton, Isaac. Opticks: or a Treatise of the Reflexions, Refractions, Inflexions and Colours of Light. Also two Treatises of the Species and Magnitude of Curvilinear Figures. London: Printed for S. Smith and B. Walford, 1704.

Rothschuh, Karl E. History of Physiology. New York: Robert E. Krieger Publishing Company, 1973.

Shapin, Steven and Schaffer, Simon (1985). Leviathan and the Air-Pump. Princeton: Princeton University Press, 1985.

Schubring, Gert. Hermann Günther Grassmann (1809-1877): Visionary Mathematician, Scientist and Neohumanist Scholar, Dordrecht: Kluwer Academic Publishers, 1996.

Temkin, Owen. "Materialism in French and German Physiology of the Early Nineteenth Century". Bulletin of the History of Medicine, 20, pp. 322-327, 1946. 
Turner, R. Steven. In the Eye's Mind: Vision and the HelmholtzHering Controversy. Princeton: Princeton University Press, 1994.

Turner, R. Steven. "The Origins of Colorimetry: What Did Helmholtz and Maxwell Learn from Grassmann". In Gert Schubring (ed.), 1996, pp. 71-86.

Young, Thomas. "On the Theory of Light and Colours". Philosophical Transactions of the Royal Society of London, 92, pp. 12-48, 1802.

$(\mathrm{cc}) \mathrm{BY}$

Manuscrito - Rev. Int. Fil. Campinas, v. 44, n. 1, pp. 37-97, Jan.-Mar. 2021. 